\title{
Technical Introduction
}

\section{Application of a Dental CAD/CAM System to the Production of All-ceramic Crowns}

\author{
Nakamura Takashi, DDS, PhD, Wakabayashi Kazumichi, DDS, PhD, \\ Kinuta Soichiro, DDS, PhD, Tanaka Hideaki, DDS, \\ Nishida Hisataka, DDS, PhD and Yatani Hirofumi, DDS, PhD \\ Department of Fixed Prosthodontics, \\ Osaka University Graduate School of Dentistry
}

\section{Clinical significance}

The effectiveness of the DECSY CAD/CAM system has been enhanced through the development of a high-speed measuring system and the availability of ceramic blocks. This system seems to be suitable for the fabrication of $\mathrm{CAD} / \mathrm{CAM}$ all-ceramic crowns.

\section{ABSTRACT}

Purpose: This article introduces the procedure for fabricating CAD/CAM all-ceramic crowns using the DECSY system in combination with the DECSY Scan and ProCAD blocks.

Materials and Methods: A working model is manufactured after preparing the abutment tooth in the usual manner. Occlusal data are obtained using soft resin occlusal registration material. By using the DECSY Scan, the abutment tooth and occlusal record are measured, and the design of the crown is calculated. Data for the completed crown are transferred to the DECSY unit, and the ProCAD ceramic block is milled. After the milling is finished, the crown is polished, and the stain porcelain fired.

Results : The CAD/CAM all-ceramic crowns were fabricated and luted. The patients were satisfied with their crowns.

Conclusion: The use of both the DECSY Scan and ProCAD blocks is recommended for the fabrication of CAD/CAM all-ceramic crowns with the DECSY system.

\section{Key words}

CAD/CAM, all-ceramic crown, linear beam laser, milling 


\section{INTRODUCTION}

All-ceramic crowns are being used with increasing frequency in both posterior and anterior regions, because of their excellent esthetic properties and biocompatibility. For this reason, much attention is being directed at dental $\mathrm{CAD} / \mathrm{CAM}$ systems that allow the fabrication of all-ceramic crowns without the need for timeconsuming laboratory work.

Two representative dental CAD/CAM systems, among the many available, are the Cerec 3 (Sirona, Bensheim, Germany), which is used in the chairside production of ceramic restorations $^{1)}$, and the Procera (Nobel Biocare, Goteburg, Sweden), which facilitates the production of ceramic or titanium copings ${ }^{2}$. However, since Cerec 3 crowns are fabricated without reference to information about the opposing teeth, it is time-consuming to make chairside adjustments. Procera is a CAD/CAM system, but it is used only to fabricate copings, so the porcelain must be fired to create the occlusal surface.

One special feature of the DECSY dental CAD/CAM system (Media, Tokyo, Japan/Digital Process, Atsugi, Japan) (Fig. 1) is that it can be used to automatically fabricate crowns with a functional occlusal surface ${ }^{3-5}$. The usefulness of this system has been further enhanced by the development of a high-speed measuring system (DECSY Scan, Media/Digital Process) (Fig. 2) and the availability of ceramic blocks (ProCAD, Ivoclar Vivadent, Schaan, Liechtenstein) with high strength and good esthetic properties ${ }^{6)}$. In this paper, we would like to introduce the clinical procedures for fabricating all-ceramic crowns using the combination of the DECSY Scan and ProCAD blocks.

\section{MATERIALS AND METHODS}

\section{Preparing the Abutment Tooth}

The preparation design for the abutment tooth is the same as for usual all-ceramic crowns. It is important to have a clearance of more than $1.5 \mathrm{~mm}$ on the occlusal surface and to prepare the finish lines as clearly as possible. The standard marginal shape is a heavy chamfer.

\section{Obtaining the Occlusal Data}

Occlusal data are obtained using "Occlusal Record", a low-temperature, thermoplastic resin occlusal registration material supplied as a system component. This material is composed of two layers : a hard layer that is used to secure the occlusal registration material to the abutment tooth and a soft layer that records the data. Softened material is secured to the abutment tooth, and a border movement is carried out in the mouth to record the information about the opposing teeth (Fig. 3).

\section{Fabricating a Working Model}

An impression is taken in the usual manner to fabricate a working model. Although the conventional DECSY system requires the use of a special type of gypsum, the newly-developed DECSY Scan makes it possible to perform measurements regardless of the type of gypsum used. The working model can be removed using a channel tray or dowel pin.

\section{Measuring with the DECSY Scan}

The working model is placed on the DECSY Scan measuring table. The type of tooth and milling material are selected on the monitor, and then the abutment tooth, adjacent teeth and occlusal record are measured ${ }^{7}$ (Fig. 4). The choices of milling materials are ceramics, titanium and wax. 
A total of six measurements using a linear beam laser are performed by turning the measuring table in 60-degree steps ; the data obtained from the six measurements are synthesized. As the measurements progress, images of the measured abutment tooth and adjacent teeth are displayed on the screen. Measurements for a single crown take about three minutes.

In an earlier version of the DECSY system, measurements were made of only the abutment tooth using a point beam laser. The new DECSY Scan takes measurements using a linear beam laser, and the time it takes for the measurements is about $1 / 5$ of the previous time.

\section{Determining the Design of the Crown}

After the measurements are complete, the design of the crown is automatically calculated in about 10 seconds. This design can be checked on the monitor (Figs. 5, 6) and can even be changed on the screen ${ }^{7}$. Data on the completed crown are transferred to the DECSY system unit.

\section{Milling the Ceramic Blocks}

ProCAD ceramic blocks are available in seven colors: three colors with two types of translucency each, and one bleach color (Fig. 7). A ProCAD block with an appropriate shade is selected according to the color of the patient's teeth and is secured on the milling unit. The block is milled using two types of diamond points : one for rough machining and the other for finishing ${ }^{7}$. Milling to shape a ceramic crown usually takes from 70 to 90 minutes (Fig. 8).

\section{Reproducing Appropriate Colors Using Stain Porcelain}

After the milling process is finished, the crown is polished. Ceramic blocks are uniform in color, so the stain or glaze porcelain supplied with the system is fired if it is desirable to reproduce a more individualized tooth color (Fig. 9)

\section{RESULTS}

Figures 10 and 11 show a clinical case of a mandibular first molar. The crown is luted using resin cement. A tooth color similar to the natural teeth can be reproduced by firing stain porcelain on the crown's surface. Figures 12 and 13 show a clinical case of such a maxillary first premolar. It is preferable to use a tooth-colored resin core for the abutment tooth, because the ceramic block is translucent. In both cases, the patients were satisfied with the results of the treatment using all-ceramic crowns and the DECSY system.

\section{DISCUSSION}

The DECSY system made its market debut as a system that allows automatic fabrication of titanium or ceramic crowns. Initially, the system used trial glass ceramic blocks with low translucency, ${ }^{3)}$ which thus posed an esthetic problem. However, ProCAD blocks have become available recently so that the esthetics of all ceramic crowns fabricated by the DECSY system have been substantially improved.

ProCAD blocks are commercially available as a component of the Cerec system ${ }^{6}$. Milled ProCAD block crowns are as strong as heatpressed all-ceramic crowns (Empress, Ivoclar Vivadent, Schaan, Liechtenstein) reinforced with the same leucite ${ }^{8)}$. It is also reported that firing of the stain or glaze porcelain onto the restoration after milling further increases the strength ${ }^{8}$, making this material suitable for the fabrication of $\mathrm{CAD} / \mathrm{CAM}$ crowns.

The DECSY system is advantageous because the time required to adjust the crowns is shorter than for the Cerec system. An intraoral occlusal adjustment of a crown made with the Cerec system takes a long time because the crown is fab- 
ricated without reference to information concerning the opposing teeth. On the other hand, occlusal adjustments using the DECSY system take less time because this system produces a functional occlusal surface that includes information about the opposing teeth.

Other CAD/CAM systems in which crowns can be fabricated using information about the opposing teeth are the Cicero ${ }^{9)}$ and Japanese $\mathrm{GN}-1^{10)}$ systems, but both of these systems require the operator to design and fabricate crowns, making the fabrication step complicated compared with the DECSY system.

Current CAD/CAM systems, such as the Procera ${ }^{2)}$, Lava ${ }^{11)}$, and DCS Precident ${ }^{12)}$, fabricate a high-strength ceramic core made of alumina or zirconia, and the porcelain is built up and fired on this core. Such a system produces crowns with excellent esthetics because a dental technician fires the porcelain. Another advantage is that these crowns have such high strength that they can be indicated for FPDs. However, these systems require the firing of porcelain, which is a complicated laboratory operation.

It is reported that there is no significant difference in the prognosis of crowns with a high-strength core fabricated by some current CAD/CAM systems and crowns using a uniform ceramic block ${ }^{13)}$ as in the DECSY system. Therefore, for patients requiring a single crown, the DECSY system seems to be a clinically effective procedure since it is possible to fabricate crowns more easily.

A further important advantage is that the high-speed measuring system (DECSY Scan) has been developed to fabricate crowns inexpensively by transferring measurement data in the same manner as in the Procera system. Longterm observation, in addition to experiments on adaptation and strength, will be necessary to determine the prognosis of ProCAD crowns.

\section{CONCLUSIONS}

1. The DECSY Scan makes it possible to shorten the time it takes to measure the working model to about $1 / 5$ of the time it previously took.

2 . The use of ProCAD blocks produces allceramic crowns with good esthetic properties and biocompatibility.

3. The DECSY system has proved to be effective for the fabrication of all-ceramic crowns.

\section{REFERENCES}

1) Mormann WH, Bindl A. The Cerec 3-a quantum leap for computer-aided restorations: Initial clinical results. Quintessence Int 31:699-712, 2000.

2) Andersson M, Razzoog ME, Oden A et al. Procera : A new way to achieve an all-ceramic crown. Quintessence Int $29: 285-296,1998$.

3) Miyazaki T, Hotta Y, Kobayashi $Y$ et al. Dental CAD/CAM system "Decsy". QDT 25:1510-1517, 2000. (in Japanese)

4) Hotta Y, Ozawa A, Kobayashi Y et al. Development of a dental CAD/CAM system fabricating dental prosthesis. J Showa Univ Dent Soc 21: 86-91, 2001. (in Japanese)

5) Tanaka T. Clinical application and present condition of DECSY/QDT Year Book 2002. 190-194, Tokyo : Quintessence, 2002. (in Japanese)

6) Fasbinder DJ. Restorative material options for CAD/CAM restorations. Compend Contin Educ Dent 23 : 911-916, 2002.

7) DECSY user's manual. 1-101, Tokyo : Media, 2004. (in Japanese)

8) Chen HY, Hickel R, Sectos JC et al. Effects of surface finish and fatigue testing on the fracture strength of CAD-CAM and pressed-ceramic crowns. J Prosthet Dent 82: 468-475, 1999.

9) Van der Zel JM, Vlaar S, de Ruiter WJ et al. The CICERO system for CAD/CAM fabrication of fullceramic crowns. J Prosthet Dent 85:261-267, 2001.

10) Hikita K, Uchiyama $Y$, Nakashizu $T$ et al. Function and potentiality of dental CAD/CAM GN-1. QDT $26: 310-318,2001$. (in Japanese)

11) Sutter D, Bunke K, Hoescheler S et al. LAVA-the system for all-ceramic $\mathrm{ZrO}_{2}$ crown and bridge frameworks. Int J Comput Dent 4:195-206, 2001.

12) Frizsche J. Zirconium oxide restorations with the DCS Precident system. Int J Comput Dent 6: 193-201, 2003.

13) Bindle A, Mormann WH. Survival rate of monoceramic and ceramic-core CAD/CAM-generated anterior crowns over 2-5 years. Eur J Oral Sci 112 : 197-204, 2004. 


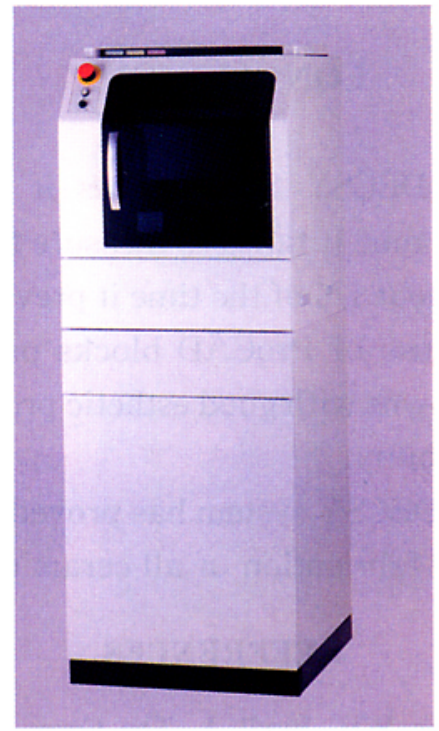

Fig. 1 DECSY Dental CAD/CAM System

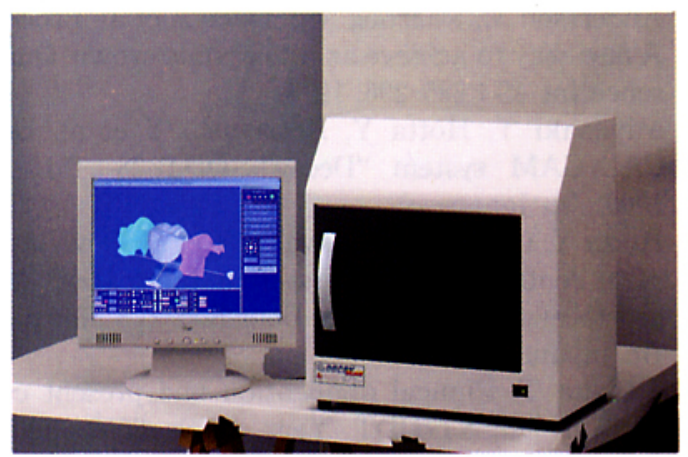

Fig. 2 High-speed measuring system (DECSY Scan)

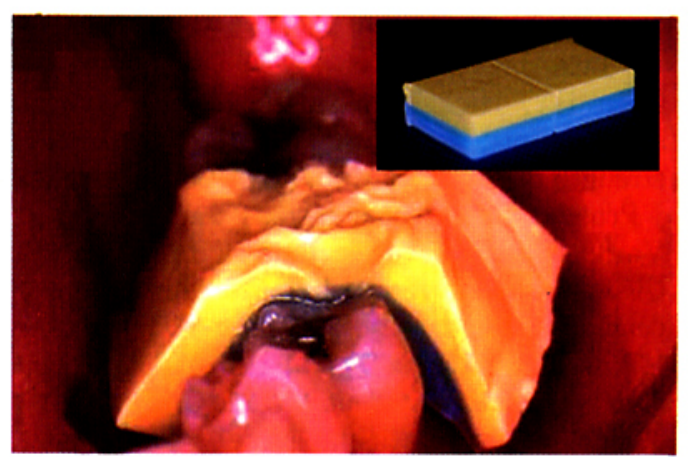

Fig. 3 "Occlusal record" is obtained using a thermoplastic resin occlusal registration material

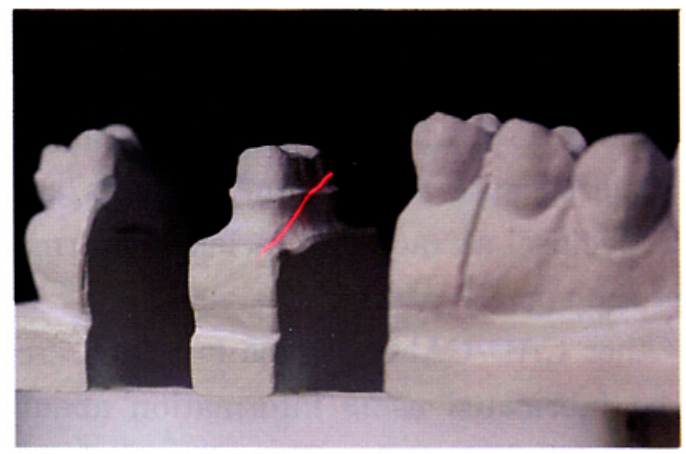

Fig. 4 The working model is measured using a linear beam laser

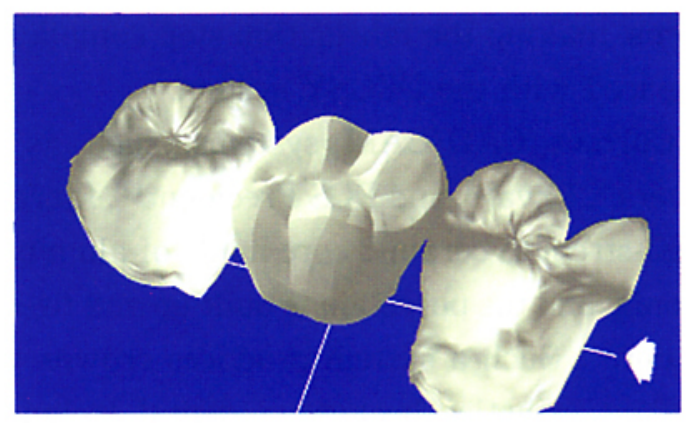

Fig. 5 The design of the first molar crown is shown on the monitor

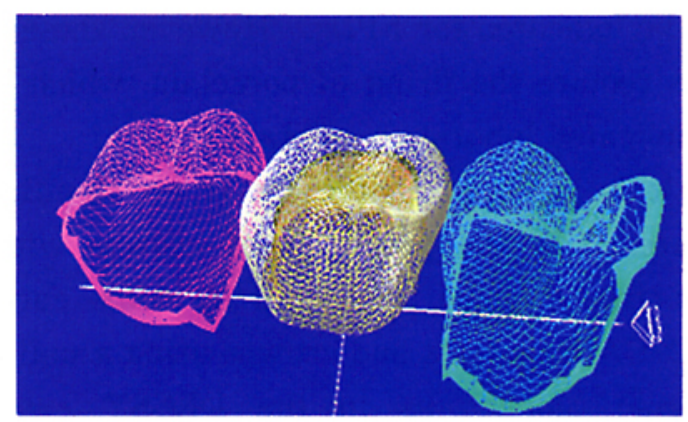

Fig. 6 The wireframe model of the designed crown 


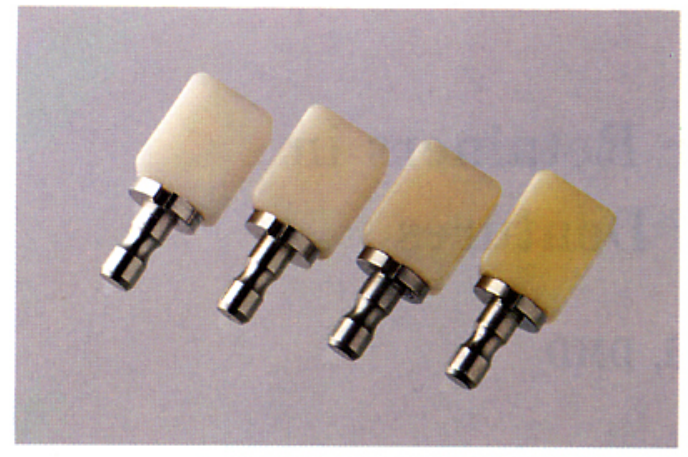

Fig. 7 ProCAD ceramic blocks

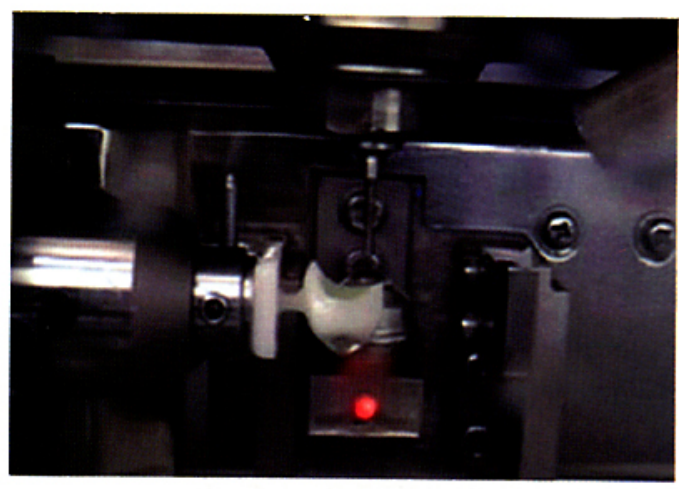

Fig. 8 The ceramic block is milled using diamond points

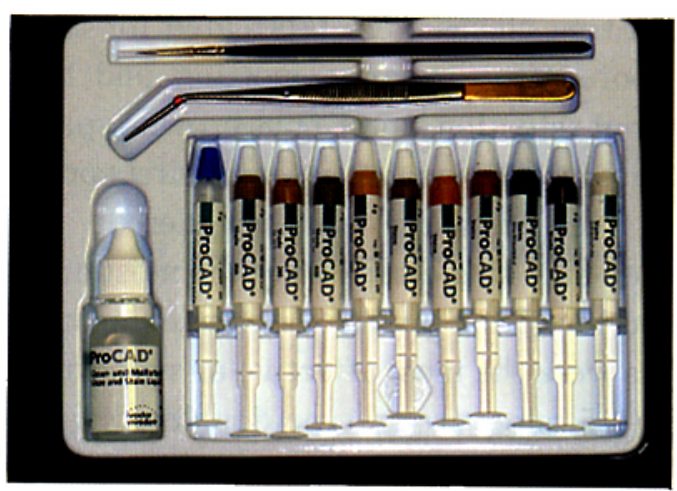

Fig. 9 The stain porcelain for ProCAD blocks

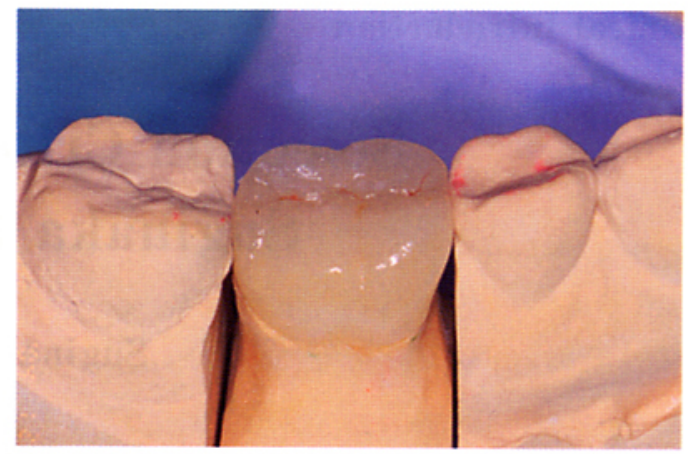

Fig. 10 Completed first molar crown

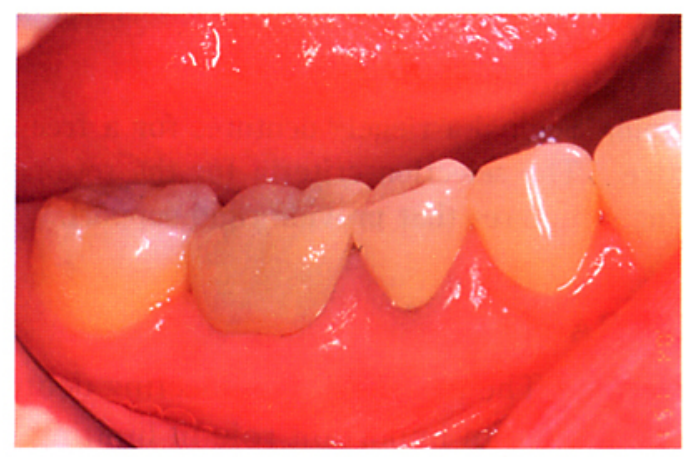

Fig. 11 Occlusal view of the CAD/CAM all-ceramic crown on the first molar

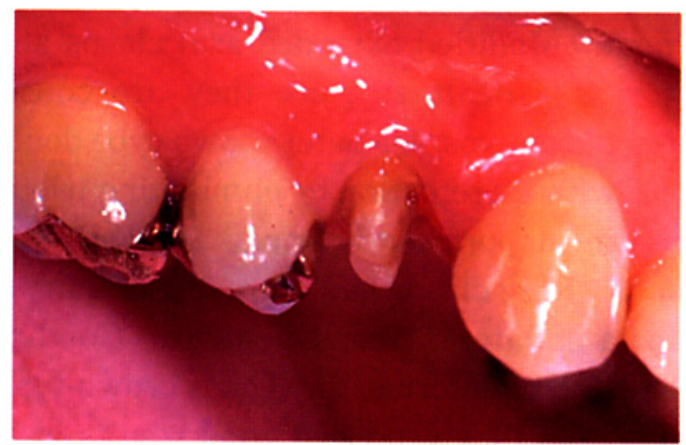

Fig. 12 After resin-core construction, an abutment tooth is prepared

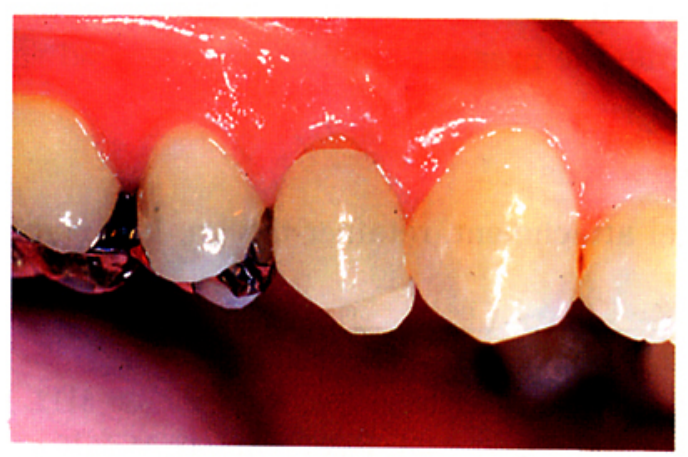

Fig. 13 Occlusal view of the crown on the first premolar 